\title{
Brushing pansy (Viola tricolor L.) transplants: a flexible, effective method for controlling plant size
}

\author{
L.C. Garner, F.A. Langton * \\ Horticulture Research International, Wellesbourne, Warwick, CV35 9EF, UK
}

\begin{abstract}
Though brushing is an effective method for controlling excessive elongation in many species, its adoption by the commercial plug transplant industry will depend on the ease and flexibility of its application. Brushing was applied to pansy (Viola tricolor L.) seedlings growing at a density of 1500 plants $\mathrm{m}^{-2}$ by daily stroking with $20 / 20$ gauge netting. In dose response experiments, final petiole length appeared to approach a lower asymptote as number of brush strokes increased, and the number of strokes required to give near full reduction in length increased under environmental conditions favouring extension growth. Ten or 20 daily strokes typically gave a $25-30 \%$ reduction in petiole elongation without causing plant damage or affecting subsequent flowering. Reductions in shoot dry weight tended to parallel those for petiole length. Increasing the interval between strokes by up to $10 \mathrm{~min}$ resulted in similar reductions as continuous brushing. There was no difference between brushing the plants at 09:00 or 16:00 h, or between brushing 1 or 2 times day $^{-1}$. Plants required at least 5 days treatment week ${ }^{-1}$ for significant size control. Brushing is an effective, flexible method for controlling petiole length in pansy and it should find application in the commercial transplant industry.
\end{abstract}

\section{Introduction}

A difficulty faced by transplant growers is to produce plants of a specified size at the scheduled time. Control of bedding plant growth with chemical growth regulators is a common practice, but the use of these chemicals is expensive, difficult and increasingly restricted. Inexpensive, non-chemical methods of height control are needed which can be 
easily adapted for commercial use. Mechanical stimulation (MS) can reduce stem and petiole elongation in a number of species (Biddington, 1986, Latimer, 1991). One type of MS, brushing, allows many plants to be stimulated at the same time.

Brushing can significantly reduce petiole length in pansy (Viola tricolor L.) without causing plant damage (Garner et al,, 1997), and there is the potential to use this technology in commercial operations if systems of brushing can be devised which are simple and flexible in their application. To this end, a series of experiments was conducted to determine the appropriate dosage and timing of brushing for pansy transplants and to characterise the daily amount, timing and number of days per week of brushing required for effective size control.

\section{Materials and methods}

\subsection{Plant culture}

Pansy seedlings ('Turbo Mix'), provided by W.J. Findon and Sons (Stratford-uponAvon, UK) were grown in 165 'plug trays' at a density of 1500 plants $\mathrm{m}^{-2}$. Plants were maintained in a glasshouse at approximately $18^{\circ} \mathrm{C}$ without supplementary lighting and were watered and fertilised with Vitafeed 19:19:19 (Vitax UK Limited, Leicester, UK) as required. Plants were brushed by hand with a flexible $20 / 20$ gauge netting (Bradley Lomas Electrolok, Ltd, Sheffield, UK), and each back and forth movement was counted as a single brush stroke. The netting was dragged carefully across the plant canopy to provide similar stem and petiole flexure with each stroke. MS was, therefore, provided by tactile stimulation of petioles and leaves, and by back and forth movement of entire shoots. Treatments were begun at the cotyledon stage of growth and continued until the plants were of a saleable size, typically after 25-30 days of treatment.

\subsection{Dose response}

A previous experiment in which only three dosage levels of brushing were investigated showed that pansy petiole length could be significantly reduced by 10 or 20 brush strokes day ${ }^{-1}$ without causing damage and without the large reductions in leaf area and shoot dry weight typically caused by 40 brush strokes day ${ }^{-1}$ (Garner et al., 1997). Experiments were conducted, therefore, to examine more closely the relationship between the number of brush strokes per day and size reduction and, if possible, to determine an optimum dosage. Plants received 5, 10, 20,30 or 40 brush strokes each morning, or were left untreated.

\subsection{Interval between brush strokes}

Two experiments were conducted to determine whether the time interval between brush strokes could be increased and still result in the same amount of height control as continuous brushing. The total daily stimulation remained constant, but the time interval between strokes was varied. Plants were either untreated, brushed continuously, or were 
brushed with a 1- or 10-min interval between paired back and forth strokes. A total of 20 brush strokes day ${ }^{-1}$ were applied in the first experiment, and 10 or 20 strokes day $^{-1}$ in the second experiment.

\subsection{Time of day}

Two experiments were conducted to determine the most appropriate time of day for effective brushing. Plants were either untreated, or were brushed in the morning (at approximately 09:00 h), in the afternoon (at approximately 16:00 h) or twice a day (half in the morning and half in the afternoon). The total number of strokes was the same for each treatment $\left(20\right.$ day $^{-1}$ in the first experiment, and 10 day $^{-1}$ in the second experiment).

\subsection{Times per week}

It would be commercially beneficial if transplants did not have to be brushed every day to maintain control of petiole elongation. Therefore, experiments were conducted in which plants were either untreated or were brushed in the morning each day, 5 days a week (Monday to Friday, inclusive), or every other day. Twenty brush strokes day ${ }^{-1}$ were applied in the first experiment and 10 strokes day $^{-1}$ in the second experiment.

\subsection{Data collection and experimental design}

At the end of the treatment period, petiole length and shoot dry weight were measured, and any damage noted. Leaf area and the number of leaves per plant were also recorded in experiments concerning the time of day and the number of days per week of application. Experiments were typically conducted using a randomised complete block design with six replications. However, a completely randomised design with four replications was used for dosage experiments. In all experiments, a quarter tray was used as the experimental unit, and ten plants from each plot were sampled for measurement. Guard rows one to two cells wide surrounded all experimental units, so that edge plants were not sampled. All the experiments were repeated in time. The first set of experiments was conducted between 27 March and 2 May, 1996, and the second between 13 May and 10 June, 1996. During the second set of experiments, shade screens were used to prevent leaf damage on sunny days. Data were analysed using analysis of variance, the Chi-square test of homogeneity and Fisher's protected LSD with 95\% confidence level (MINITAB, 1995).

\section{Results}

\subsection{Dose response}

In both experiments, the mean petiole length and mean shoot dry weight of brushed plants were significantly less than those of untreated plants (Table 1). There were no significant differences between the five brushing treatments for either variate in Experi- 
Table 1

The effect of the number of brush strokes per day on the growth of pansy transplants

\begin{tabular}{|c|c|c|c|c|}
\hline \multirow[t]{2}{*}{ Brush strokes per day } & \multicolumn{2}{|c|}{ Petiole length (mm) } & \multicolumn{2}{|c|}{ Shoot dry weight (mg) } \\
\hline & Expt 1 & Expt 2 & Expt 1 & Expt 2 \\
\hline None & 12.8 & 20.2 & 59 & 80 \\
\hline 5 & 10.0 & 17.4 & 52 & 75 \\
\hline 10 & 9.3 & 15.0 & 50 & 63 \\
\hline 20 & 9.6 & 14.0 & 51 & 62 \\
\hline 30 & 10.1 & 13.3 & 45 & 49 \\
\hline 40 & 9.8 & 12.8 & 50 & 54 \\
\hline Brushed vs untreated & $* * *$ & $* * *$ & ${ }^{x}$ & $* * *$ \\
\hline Linear trend & NS & $* * *$ & NS & $* x *$ \\
\hline SE & 0.55 & 0.85 & 4.1 & 4.1 \\
\hline $\operatorname{LSD}_{0.05}(18$ d.f. $)$ & 1.62 & 2.51 & - & 12.3 \\
\hline
\end{tabular}

NS, ${ }^{* * *},{ }^{* *},{ }^{*}$, main effects within column not significant at $P=0.05$ or significant at $P<0.001,0.01$ or 0.05 , respectively. Trends other than linear were non-significant at $P=0.05$.

ment 1. However, in Experiment 2, a significant linear trend over the five brushing treatments was shown $(P=0.001)$, with reductions in petiole length and shoot dry weight as the number of brush strokes increased.

Although trends other than linear were formally non-significant at $P=0.05$ in Experiment 2, visual inspection of the data (Table 1) suggested that both height and shoot dry weight approached a lower limit as the number of brush strokes increased. This was modelled by fitting the function $y=a+b /(1+c x)$, where $x=$ number of brush strokes, $a=$ the lower asymptote and $a+b=$ response when $x=0$. For petiole length (see Fig. 1), this model gave a better fit to the data than did the linear trend model (with untreated control). Respective lack of model fit sums of squares for the two models were $1.640 \mathrm{~mm}^{2}$ and $9.451 \mathrm{~mm}^{2}$, both with 3 d.f. Estimates of parameters were: $a=11.09 \mathrm{~mm}(\mathrm{SE}=1.39 \mathrm{~mm}) ; b=9.21 \mathrm{~mm}(\mathrm{SE}=1.44 \mathrm{~mm}) ; c=0.1101 \quad(\mathrm{SE}=$ 0.0583 ). Similarly, a better fit was obtained for the asymptotic model than the linear response model (with untreated control) for shoot dry weight, with respective lack of

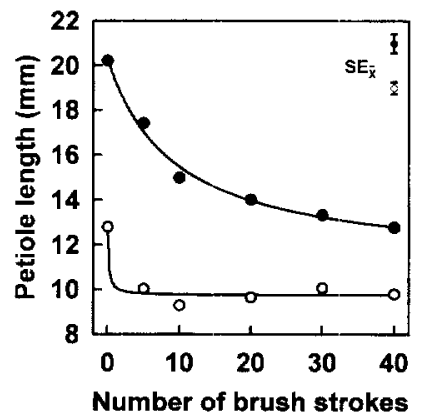

Fig. 1. Relationships between numbers of brush strokes and petiole length in Experiment $1(0)$ and Experiment $2(-)$. Fitted curves are for the function $y=a+b /(1+c x)$ (see text). 
model fit sums of squares of $271.34 \mathrm{mg}^{2}$ and $428.10 \mathrm{mg}^{2}$ (d.f. $=3$ ). Estimates of parameters were: $a=37.8 \mathrm{mg}(\mathrm{SE}=14.7 \mathrm{mg}) ; b=43.2 \mathrm{mg}(\mathrm{SE}=13.7 \mathrm{mg}) ; c=0.0530$ $(\mathrm{SE}=0.0463)$.

No such trend was apparent for Experiment 1, although it is possible that the response to brushing was essentially as in Experiment 2, but already approaching full expression after the application of five brush strokes. Fits to the asymptotic model (Fig. 1) and the linear response model (with untreated control) for petiole length were similar, with respective lack of model fit sums of squares of $1.590 \mathrm{~mm}^{2}$ and $1.517 \mathrm{~mm}^{2}$ (d.f. $=3$ ). Similar fits were also given to the two models for shoot dry weight, lack of model fit sums of squares being $70.71 \mathrm{mg}^{2}$ and $80.70 \mathrm{mg}^{2}$, respectively (d.f. $=3$ ).

Though 5 strokes day ${ }^{-1}$ did cause a statistically significant decrease in petiole length in Experiment 2 (a decrease in petiole length of about 14\%) the stimulus was judged to be insufficient to be of practical importance to the grower. In both experiments, 30 or 40 brush strokes day ${ }^{-1}$ caused noticeable plant damage.

\subsection{Time interval between strokes}

In both experiments, brushing significantly reduced petiole length, but there were no significant differences between the three brushing treatments (Table 2). Shoot dry weight was not significantly affected by brushing and there was no noticeable damage in either experiment. More importantly, contrasts between continuous and non-continuous brushing and between 1- and 10-min intervals were not significant for any measured variate in either experiment.

\subsection{Time of day}

Petiole length, leaf area and shoot dry weight were all significantly decreased by brushing, though there were no significant differences between the three brushing

Table 2

The effect of varying the time interval between paired brush strokes on the growth of pansy transplants

\begin{tabular}{lccccc}
\hline \multirow{2}{*}{ Method of brushing } & \multicolumn{2}{c}{ Petiole length $(\mathrm{mm})$} & & \multicolumn{2}{c}{ Shoot dry weight $(\mathrm{mg})$} \\
\cline { 2 - 3 } \cline { 5 - 6 } & Expt 1 & Expt 2 & & Expt 1 & Expt 2 \\
\hline None & 12.2 & 18.5 & 63 & 65 \\
Continuous & 10.0 & 17.1 & 60 & 71 \\
1-min intervals & 9.5 & 16.3 & 54 & 70 \\
10-min intervals & 9.6 & 16.1 & 56 & 64 \\
Brushed vs untreated & $* * *$ & $*$ & NS & NS \\
Continuous vs non-continuous & NS & NS & NS & NS \\
1-vs 10-min intervals & NS & NS & NS & NS \\
SE & 0.47 & 0.92 & 2.8 & 4.1 \\
LSD $_{0.05}$ (15 d.f.) & 1.57 & - & - & - \\
\hline
\end{tabular}

NS, ${ }^{* *},{ }^{* *},{ }^{*}$, main effects within column not significant at $P=0.05$ or significant at $P<0.001,0.01$ or 0.05 , respectively. 
Table 3

The effect of time of day of brushing on the growth of pansy transplants

\begin{tabular}{|c|c|c|c|c|c|c|}
\hline \multirow[t]{2}{*}{ Time and frequency of daily brushing } & \multicolumn{2}{|c|}{ Petiole length $(\mathrm{mm})$} & \multicolumn{2}{|c|}{ Leaf area $\left(\mathrm{cm}^{2}\right)$} & \multicolumn{2}{|c|}{ Shoot dry weight (mg) } \\
\hline & Expt 1 & Expt 2 & Expt 1 & Expt 2 & Expt 1 & Expt 2 \\
\hline None & 15.4 & 18.6 & 12.35 & 15.57 & 80 & 88 \\
\hline Morning and afternoon & 12.0 & 16.6 & 10.56 & 13.44 & 73 & 77 \\
\hline Morning only & 12.8 & 16.1 & 10.31 & 11.94 & 70 & 70 \\
\hline Afternoon only & 12.3 & 15.6 & 10.52 & 12.58 & 72 & 73 \\
\hline Brushed vs untreated & $* * *$ & $*$ * & $\approx *$ & $\times *$ & * & $* *$ \\
\hline 1 vs 2 applications day ${ }^{-1}$ & NS & NS & NS & NS & NS & NS \\
\hline Morning vs afternoon & NS & NS & NS & NS & NS & NS \\
\hline $\mathrm{SE}$ & 0.45 & 0.76 & 0.530 & 0.738 & 3.5 & 4.0 \\
\hline $\mathrm{LSD}_{0.05}(15$ d.f. $)$ & 1.15 & 1.64 & 1.116 & 2.328 & - & 11.6 \\
\hline
\end{tabular}

NS, ${ }^{* * *},{ }^{* *},{ }^{*}$, main effects within column not significant at $P=0.05$ or significant at $P<0.001,0.01$ or 0.05 , respectively.

treatments for any of these variates (Table 3). The number of leaves per plant appeared independent of the time of day of brushing in both experiments (data not shown) and there was no noticeable damage in either experiment. Furthermore, contrasts between 1 and 2 treatment applications day ${ }^{-1}$, and between morning and evening treatments, were not significant for any measured variate in either experiment.

\subsection{Times per week}

Treated plants typically had significantly shorter petioles than untreated plants (Table 4). In Experiment 1, there was a significant negative linear relationship between petiole length and the number of times per week that the plants were treated. Brushing every

Table 4

The effect of the frequency of brushing per week on the growth of pansy transplants

\begin{tabular}{|c|c|c|c|c|c|c|}
\hline \multirow[t]{2}{*}{ Frequency of brushing } & \multicolumn{2}{|c|}{ Petiole length (mm) } & \multicolumn{2}{|c|}{ Leaf area $\left(\mathrm{cm}^{2}\right)$} & \multicolumn{2}{|c|}{ Shoot dry weight ( $\mathrm{mg}$ ) } \\
\hline & Expt 1 & Expt 2 & Expt 1 & Expt 2 & Expt 1 & Expt 2 \\
\hline None & 12.4 & 16.8 & 9.28 & 13.38 & 65 & 80 \\
\hline Alternate days per week & 11.5 & 15.4 & 8.34 & 12.04 & 61 & 75 \\
\hline 5 consecutive days week ${ }^{-1}$ & 10.4 & 14.4 & 7.80 & 10.63 & 56 & 68 \\
\hline 7 days week $^{-1}$ & 9.6 & 14.2 & 7.06 & 11.73 & 53 & 75 \\
\hline$F$ test overall & $* * *$ & NS & $* * *$ & NS & $* * *$ & NS \\
\hline Brushed vs untreated & $* * *$ & NS & $* * *$ & NS & $* * *$ & NS \\
\hline Linear trend $^{\mathrm{a}}$ & $* *$ & NS & $* *$ & NS & $* * *$ & NS \\
\hline SE & 0.35 & 0.90 & 0.270 & 0.841 & 2.1 & 4.2 \\
\hline $\mathrm{LSD}_{0.05}(15 \mathrm{~d} . \mathrm{f})$. & 1.06 & - & 0.675 & - & 4.0 & - \\
\hline
\end{tabular}

${ }^{a}$ Based on brushing $3.5,5$ or 7 days week ${ }^{-1}$.

NS, ${ }^{* * *},{ }^{* *}$, main effects within column not significant at $P=0.05$ or significant at $P<0.001$ or 0.01 , respectively. There were no significant quadratic trends. 
other day was the only treatment that did not provide a sufficient or significant decrease in petiole length relative to unbrushed plants. A similar trend was noted for the petiole length data in Experiment 2, though this was not significant. There was a significant negative relationship between both the leaf area and shoot dry weight and the number of times per week that the plants were brushed in Experiment 1. The leaf area and shoot dry weight were not significantly affected by any of the brushing treatments in Experiment 2. The number of leaves per plant seemed independent of the brushing treatments in both experiments (data not shown). There was no noticeable plant damage in either experiment.

\section{Discussion}

Environmental conditions in experiments to determine the effects of dosage were such that petiole lengths were substantially greater in Experiment 2 (summer) than in Experiment 1 (spring). Under the conditions of Experiment 2, length approached a lower limit with increasing number of strokes. A similar asymptotic response may have been shown in Experiment $I$ but was missed because as few as five brush strokes invoked near maximum reduction. Whether or not this is an accurate interpretation of the biological response of pansy to stimulation by brushing, it is apparent that numbers of strokes required to achieve full or near full growth reduction are likely to be greater under conditions favouring extension growth than under conditions less favourable to growth. In practice, 10-20 brush strokes can be expected to give a commercially useful response $(25-31 \%$ reduction) at any time of year without causing plant damage. Associated reductions in shoot dry weight are likely to be of a similar or smaller percentage magnitude.

In a previous experiment with tomato (Lycopersicon esculentum Mill.) transplants, the response to brushing was also easily saturated (Garner and Björkman, 1996), as it was with the pansy transplants in Experiment 1. Other researchers have reported a negative relationship between the amount of stimulation given and the plant height of a number of species (Beyl and Mitchell, 1977, Heuchert and Mitchell, 1983, Autio et al., 1994), and these results are similar to those obtained with the pansy transplants in Experiment 2. What is consistent among all of these experiments is that a relatively small amount of brushing can provide a significant and noticeable reduction in transplant size. Further brushing of the plants only increases the risk of damage and the effort associated with brushing, without substantially increasing the benefits of the treatment.

Pansy plants which had been brushed continuously 20 times day $^{-1}, 7$ days week $^{-1}$, were subsequently potted up in the greenhouse alongside control plants, and brushing was discontinued. This demonstrated that brushing had no adverse effect on flowering after transplanting; there was no delay in the appearance of flowers and no increase in the number of days to $50 \%$ flowering (data not shown). Brushing also caused no damage to the flowers.

The results of the experiments on increasing the time interval between strokes were consistent with those of a similar experiment using tomato transplants (Garner and Björkman, 1996). For both species, the time interval between strokes can be at least 10 
min long, and still result in similar size control as continuous stimulation. It is not necessary for pansy plants to receive daily brushing in a series of continuous strokes. This provides flexibility for commercial application, especially if the technique is to be automated.

The effectiveness of brushing was not significantly influenced by the time of day of its application. The response of tomato plants to MS is also typically unaffected by the time of day of treatment application (Heuchert and Mitchell, 1983, Garner and Björkman, 1996), though chrysanthemums (Dendranthema $\times$ grandiflorum (Ramat.) Kitam.) are slightly more sensitive to MS in the morning (Beyl and Mitchell, 1977). Results from the pansy experiments, however, are not consistent with research showing that tomato plant height is more greatly reduced by two or more small daily vibration treatments than by one daily equivalent treatment (Mitchell et al., 1975, Piszczek and Jerzy, 1987). This difference between the response of tomato and pansy plants could be real, but it might also reflect, in part, the increased amount of handling required to place the tomato plants on a gyratory shaker several times each day.

In commercial practice, the timing of brushing pansy transplants should be extremely flexible. There were no statistical differences between treating the plants once each day (20 or 10 strokes) or twice each day (ten or five strokes), or between treating them in the morning or the afternoon. The choice of the best time of day for brushing can be left to the individual grower, and could even be determined on a daily basis to minimise interference with production practices and to avoid brushing the plants when they are either wilting or wet.

The results of experiments on the number of treatments per week were consistent with previous research in which decreasing the nurnber of days per week on which lettuce (Latuca sativa L.) transplants were brushed decreased the effectiveness of treatment (Wurr and Fellows, 1986). However, for both lettuce and pansy transplants, some reduction in the frequency of brushing can be tolerated. In Experiment 1, brushing for only 5 days week ${ }^{-1}$ provided a significant decrease in petiole length while minimising reductions in leaf area and shoot dry weight. Whilst brushing at least 1 time day $^{-1}$ has been recommended for the height control of tomato and cucumber ( $\mathrm{Cucumis}$ sativus L.) transplants (Latimer, 1992), this does not appear to be necessary for pansy transplants.

It is concluded that brushing is a sufficiently flexible technique to be integrated with commercial production practices. Pansy transplants require only a small amount of daily stimulation to achieve maximum growth reduction, and the dosage can be adjusted to suit the growth rate of the crop. It is likely that the degree of growth control achieved with 10-20 brush strokes day ${ }^{-1}$ will fully satisfy commercial requirements in the spring and autumn periods when the extension growth of pansy is naturally limited, but some additional control by the use of chemical growth regulators may be required in the more difficult summer period. However, brushing will greatly reduce the numbers of growth regulator applications needed or the concentrations required. The timing of the stimulation is not critical. Plants can be brushed at a time when the grower finds it most convenient, and brushing does not have to be applied continuously. Plants do not have to be brushed every day, although treatment on at least 5 days week ${ }^{-1}$ is likely to be necessary for effective size control. The response of plants to MS varies with species, 
but this and other work consistently show that the magnitude of the response to MS is not greatly affected by altering the dosage or timing of the stimulation.

Some form of mechanisation is essential in order to exploit the utility of brushing in commercial practice, and trials to achieve this have begun at W.J. Findon and Sons (Stratford-upon-Avon, UK). Suspending netting from the travelling irrigation booms (whilst irrigation is not being supplied), so that the netting is dragged backwards and forwards over the plug trays on the benches below, may provide a simple and effective solution.

\section{Acknowledgements}

The authors gratefully acknowledge the financial support provided by Horticulture Research International, the Horticultural Development Council, East Malling, UK and W.J. Findon and Sons, Stratford-upon-Avon, UK. Particular thanks are also due to $\mathrm{Mr}$ Rodney Edmondson and a referee for assistance with statistical analysis.

\section{References}

Autio, J.A., Voipio, I., Koivunen, T., 1994. Responses of aster, dusty miller, and petunia seedlings to daily exposure to mechanical stress. HortScience 29 (12), 1449-1452.

Beyl, C.A., Mitchell, C.A., 1977. Characterization of mechanical stress dwarfing in chrysanthemum. J. Am. Soc. Hortic. Sci. 102 (5), 591-594.

Biddington, N.L., 1986. The effects of mechanically-induced stress in plants-a review. Plant Growth Regul. 4, 103-123.

Garner, L.C., Björkman, T., 1996. Mechanical conditioning for controlling excessive elongation in tomato transplants: sensitivity to dose, frequency and timing of brushing. J. Am. Soc. Hortic. Sci. 121 (5), 894-900.

Garner, L.C., Langton, F.A., Björkman, T., 1997. Commercial adaptations of mechanical stimulation for the control of transplant growth. Acta Hortic. 435, 219-230.

Heuchert, J.C., Mitchell, C.A., 1983. Inhibition of shoot growth in greenhouse-grown tomato by periodic gyratory shaking. J. Am. Soc. Hortic. Sci. 108 (5), 795-800.

Latimer, J.G., 1991. Mechanical conditioning for control of growth and quality of vegetable transplants. HortScience 26, 1456-1461.

Latimer, J.G., 1992. For height control, give transplants the brush. Am. Veg. Grow. 40 (4), 62, 65, 68, 69.

MINITAB, 1995. Release 10 Xtra. Minitab Inc., State College, PA, USA.

Mitchell, C.A., Severson, C.J., Wott, J.A., Hammer, P.A., 1975. Seismomorphogenic regulation of plant growth. J. Am. Soc. Hortic. Sci. 100 (2), 161-165.

Piszczek, P.M., Jerzy, M., 1987. The response of tomato (Lycopersicon esculentum Mill.) transplants to mechanical stress. Acta Agrobot. 40, 5-14.

Wurr, D.C.E., Fellows, J.R., 1986. The influence of supplementary lighting and mechanically induced stress during plant raising, on transplant and maturity characteristics of crisp lettuce. J. Hortic. Sci. 61 (3), $325-330$. 